\title{
Editorial
}

\section{Nutrition and oral health in sport: time for action}

Ian Needleman ${ }^{1,2}$, Paul Ashley ${ }^{1,2}$, Tom Fairbrother ${ }^{3}$, Peter Fine ${ }^{4}$, Julie Gallagher ${ }^{1,2}$, Daniel Kings ${ }^{5}$, Ron Maughan ${ }^{6}$, Anna Melin \& Mike Naylor ${ }^{8}$

${ }^{1}$ Centre for Oral Health and Performance, UCL Eastman Dental Institute, London UK

${ }^{2}$ UK IOC Research Centre for Prevention of illness and Protection of Athlete Health

${ }^{3}$ Communication Executive, Parkrun, UK

${ }^{4}$ Continuing Professional Development, UCL Eastman Dental Institute, London UK

${ }^{5}$ Aspetar, Doha, Qatar

${ }^{6}$ Emeritus Professor of Sport Science Nutrition, Loughborough University, UK

${ }^{7}$ Department of Nutrition, Exercise and Sports, Institute of Preventive and Clinical Nutrition, University of Copenhagen Denmark

${ }^{8}$ Performance Nutrition, English Institute of Sport, UK

\section{Corresponding author}

Prof. Ian Needleman

Centre for Oral Health \& Performance, UCL Eastman Dental Institute, 256 Gray's Inn Road, London WC1X 8LD, UK

Key words: Oral health, Sports Medicine, Athletic Performance, Diet, Sports Nutritional Physiological Phenomena, Feeding and Eating Disorders 


\section{What's the problem?}

Elite athletes have poor oral health, common negative self-reported performance effects and a lifelong burden for disease management ${ }^{1-3}$. One central determinant of oral health is nutrition and in particular the consumption of dietary sugars, acidic food and drinks and eating behaviours. However, nutrition is also clearly of major importance in managing and improving athlete performance. Therefore, this call to action is to recommend strategies to prevent or mitigate the risk from nutrition to the short-term health and performance of athletes and to the long-term oral health of all active individuals. The target audience includes athletes, health professionals (nutritionists and dieticians, sport and exercise medicine practitioners, dental professionals), scientists in related fields, sport policy organisations and industry.

\section{Call to action}

Given that the mechanisms by which carbohydrate-containing or acidic supplements can affect oral health are well established, it is important to develop mitigation strategies to reduce the risk of possible adverse oral effects whilst maintaining the performance benefits. Based on best evidence for effectiveness ${ }^{4}$, we recommend:

1. Avoid supplements not benefiting training, competition or recovery: Discourage the use of beverages and supplements containing sugars linked to poor oral health outside of a specific training regimen or competition prescribed by a qualified nutritionist and identify suitable alternatives. For instance, for post-event hydration, milk could be substituted for proprietary sports drinks, and plain water is adequate if combined with electrolyte and carbohydrate containing foods such as those normally eaten during the recovery period ${ }^{5}$. A 'food first' approach should be taken over the use of supplements.

2. Modify the oral environment: Where carbohydrate or acidic supplements are used regularly, high concentration fluoride toothpastes (at least 2,800ppm) are a priority and should be substituted for standard toothpastes twice per day to reduce the solubility of tooth enamel. Where these are not available a toothpaste with at least 1,350ppm fluoride should be used. It is recommended that athletes spit but don't rinse after toothbrushing to maximise the benefit of the fluoride availability. In addition, a $0.05 \%$ sodium fluoride mouthrinse should be used at a different time of the day (e.g. middle of day). In practical terms fluoride supplementation is likely to be indicated for many athletes. The reported impairment by mouthrinses of the conversion of nitrate to nitrite for ergogenic supplementation appears to be caused by the antimicrobial chlorhexidine and not fluoride or the alcohol found in many mouthrinses ${ }^{6}$. 
Furthermore, the evidence does not support a link between alcohol-containing mouthrinses and oral cancer.

3. Reduce the dental plaque biofilm (oral hygiene): Dental caries and periodontal diseases are caused by the dental plaque biofilm. The effects of the biofilm may be enhanced in athletes due to reduction of protection from saliva due to dehydration and high volume airflow, a proinflammatory effect of frequent carbohydrate intake and modulation of the immune response by intensive training and stress ${ }^{7}$. Therefore, effective oral hygiene becomes particularly important. To achieve this requires:

a. Personalised technique coaching and instruction from a dental professional (dentist, hygienist, oral health educator etc.). The athlete should take responsibility for their daily self-care.

b. Interdental cleaning (interdental brushes or floss) before toothbrushing (manual or powered toothbrush)

c. Athlete self-monitoring for instance using plaque-disclosing solutions

4. Routine periodic oral health assessment. This should include screening for disease, assessment of oral hygiene and additional coaching and instruction as needed by a dental professional ${ }^{8}$. Current data suggest a frequency of twice-yearly and particularly pre-season.

5. Disordered eating can first show as tooth erosion. Elite athletes are at increased risk of disordered eating behaviour which can seriously affect physical and mental health and may be otherwise difficult to detect. Dental professionals can play an important role in identifying athletes with these conditions since erosive toothwear can be one of the earliest detectable signs.

6. Other simple risk mitigation strategies: Where possible, use a two-bottle strategy e.g. sport supplement, followed by water.

7. Implementation research: Studies are needed to identify best approaches for implementation of the recommendations in different sport environments. Research should be based on valid behaviour change science and adopt ecological considerations of athletes and support team structures.

\section{2 words}




\section{Expertise and contribution to paper}

Ian Needleman' Paul Ashley and Julie Gallagher are clinical academic researchers in oral health. Ron Maughan, Anna Melin and Dan Kings are researchers in nutrition. Mike Naylor is Head of Nutrition, English Institute of Sport. Georgie Bruinvels is an academic researcher in female athlete health and athlete. Tom Fairbrother is a sport and exercise scientist, communications manager for Parkrun global and athlete. Peter Fine is a senior teaching fellow in oral health. Ian Needleman \& Paul Ashley wrote the first draft of the paper. All authors contributed to revision of the draft. The recommendations were discussed and agreed with participants at a symposium, Nutrition, Oral Health \& Performance, University College London 28th July 2017.

\section{Funding \& competing interests}

The following organisations supported the symposium but had no input into the development or content of the paper: Institute for Sport Exercise \& Health (ISEH), GlaxoSmithKline \& the BDJ. The authors declare that there were no competing interests in their involvement or input into the paper. 


\section{References}

1. Needleman I, Ashley P, Petrie A, et al. Oral health and impact on performance of athletes participating in the London 2012 Olympic Games: a cross-sectional study. British Journal of Sports Medicine 2013;47:1054-58.

2. Needleman I, Ashley P, Meehan L, et al. Poor oral health including active caries in 187 UK professional male football players: clinical dental examination performed by dentists. British Journal of Sports Medicine 2016;50:41-44.

3. Gallagher J, Ashley P, Petrie A, et al. Oral health and impact on performance in elite and professional sport. British Journal of Sports Medicine 2017; Monaco abstracts 51: 320-321; DOI: 10.1136/bjsports-2016-097372.94

4. Public Health England. Delivering better oral health: an evidence-based toolkit for prevention. 3rd Edition. PHE 20142014.

www.gov.uk/government/uploads/system/uploads/attachment data/file/367563/DBOHv320 140CTMainDocument 3.pdf. (accessed January 2018)

5. Shirreffs SM, Sawka MN. Fluid and electrolyte needs for training, competition, and recovery. Journal of Sports Sciences: 2011:29: Suppl 1, S39-S46.

6. Govoni M, Jansson EA, Weitzberg E, et al. The increase in plasma nitrite after a dietary nitrate load is markedly attenuated by an antibacterial mouthwash. Nitric Oxide : Biology and Chemistry 2008;19:333-7.

7. Gleeson M. Immune function in sport and exercise. Journal of Applied Physiology 2007;103:693-99.

8. Needleman I, Ashley P, Weiler R, et al. Oral health screening should be routine in professional football: a call to action for sports and exercise medicine (SEM) clinicians. British Journal of Sports Medicine 2016; 50:1295-96. 